\title{
Non-invasive prenatal testing (NIPT): societal pressure or freedom of choice? A vignette study of Dutch citizens' attitudes
}

\author{
Adriana Kater-Kuipers $\mathbb{1}^{1} \cdot$ Iris M. Bakkeren ${ }^{2} \cdot$ Sam R. Riedijk ${ }^{2}$ - Attie T.J.I. Go ${ }^{3} \cdot$ Marike G. Polak $\mathbb{D}^{4} \cdot$ \\ Robert-Jan H. Galjaard ${ }^{2}$ - Inez D. de Beaufort ${ }^{1}$ - Eline M. Bunnik ${ }^{1}$
}

Received: 7 November 2019 / Accepted: 15 June 2020 / Published online: 5 August 2020

(c) The Author(s), under exclusive licence to European Society of Human Genetics 2020

\begin{abstract}
The introduction of the accurate and procedurally easy non-invasive prenatal test (NIPT) raises ethical concerns that public attitudes towards prenatal screening may change, leading to societal pressure to participate in aneuploidy screening. This study examined Dutch citizens' attitudes towards a pregnant woman's decision to (1) decline NIPT in the context of two different funding policies and (2) to terminate or continue a pregnancy affected by different disorders. The attitudes of 1096 respondents were assessed with the contrastive vignette method, using two pairs of vignettes about declining NIPT and termination of pregnancy. Most respondents either agreed with a woman's decision to decline NIPT or were neutral about it, stating that this decision should be made independently by women, and does not warrant judgement by others. Interestingly, funding policies did influence respondents' attitudes: significantly more respondents disagreed with declining NIPT when it was fully reimbursed. Respondents had similar attitudes to the vignettes on termination and continuation of pregnancy in case of Down's syndrome. In case of Edwards' or Patau's syndrome, however, significantly more respondents disagreed with continuation, citing the severity of the disorder and the child's best interests. This study demonstrates broad acknowledgement of women's freedom of choice in Dutch society; a finding that may help to rebut existing concerns about societal pressure for pregnant women to participate in prenatal screening. As the reimbursement policy and the scope of NIPT may influence people's attitudes and elicit moral judgements, however, maintaining freedom of choice warrants sustained efforts by health professionals and policy makers.
\end{abstract}

Supplementary information The online version of this article (https:// doi.org/10.1038/s41431-020-0686-9) contains supplementary material, which is available to authorised users.

$\triangle$ Adriana Kater-Kuipers

a.kater-kuipers@erasmusmc.nl

1 Department of Medical Ethics and Philosophy of Medicine, Erasmus MC, University Medical Centre Rotterdam, Rotterdam, The Netherlands

2 Department of Clinical Genetics, Erasmus MC, University Medical Centre Rotterdam, Rotterdam, The Netherlands

3 Department of Obstetrics and Gynecology, Erasmus MC, University Medical Centre Rotterdam, Rotterdam, The Netherlands

4 Department of Psychology, Education \& Child Studies (DPECS), Erasmus University Rotterdam, Rotterdam, The Netherlands

\section{Introduction}

The aim of offering prenatal screening for aneuploidies is promoting women's and couples' reproductive autonomy [1]. This implies that women and couples make their personal decision about prenatal screening according to their life plan and values, and it precludes any form of pressure to accept or decline prenatal screening. However, women's freedom of choice is subject of concern with the introduction of non-invasive prenatal testing (NIPT) [2]. The current study explores whether there are public attitudes towards NIPT in the Netherlands which might give rise to societal pressure to participate in screening.

NIPT is offered as an alternative to- - or in lieu of - the first-trimester combined test for trisomy 21, 18 and 13, or Down's, Edwards' and Patau's syndrome respectively. NIPT allows for the analysis of cell-free foetal DNA in maternal blood using genome-wide sequencing techniques. It only requires a blood draw from the mother, while the firsttrimester combined test also includes an ultrasound scan. 
Furthermore, NIPT is more reliable than the first-trimester combined test which provides a risk estimation for these three trisomies [3]. With both testing modalities, abnormal test results must be confirmed by an invasive follow-up diagnostic test. Because of its higher specificity, NIPT leads to fewer follow-up tests than the combined test. These favourable characteristics of NIPT however raise ethical and social concerns and are amongst others believed to change the informed decision making process and lead to selfevident acceptance of NIPT-a concern often referred to as 'routinisation' [4]. It is feared that NIPT takes away reasons for women to deliberate or reject the screening offer [5] or provokes the feeling that women have to justify themselves when they decline an easy and reliable prenatal test $[6,7]$. These consequences are thought to lead to societal pressure to test. Such societal pressure poses a threat to reproductive autonomy and thus to the aim of prenatal screening [4].

Testing this hypothesis is a challenge because it is difficult to assess whether societal pressure to participate in screening exists at all—or what exactly societal pressure is. We interpret societal pressure not as pressure exerted by the state (e.g., mandatory screening programmes) or by health professionals (e.g., directive counselling). In the countries in which NIPT is currently being introduced, screening is offered on a voluntary basis and women are not forced or coerced by their health professionals to take part.

Instead, we take societal pressure to be associated with explicit positive societal attitudes towards prenatal screening [8], negative explicit or implicit societal attitudes towards people with a disability [9], holding parents (financially) accountable for the birth of a disabled child or with suggesting that raising a disabled child is one's own (financial) responsibility [10]. Moreover, societal pressure can be associated with pressure to abort an affected pregnancy, e.g., fearing that people may perceive giving birth to a disabled child as irresponsible [5, 10]. Dutch parents of children with Down's syndrome, for example, have collected their experiences with societal critique on having a child with Down's syndrome in a book titled 'Blackbook Down's syndrome, all people are unequal and similar' [11]. This book for example includes judgements that parents 'could have known that their child has Down's syndrome with prenatal screening' and that 'it is not necessary to have such a child because they could have terminated the pregnancy'. The experienced or feared societal pressure to test and to terminate a pregnancy of a child with Down's syndrome was also mentioned in qualitative studies amongst parents of children with Down's syndrome [10, 12, 13]. Besides, in the Netherlands, women must make a copayment of $€ 175$ for NIPT. Funding policies are thought to influence the routine practice of prenatal screening [14] and possibly therewith societal pressure to test: a prenatal screening offer which is paid with government subsidies might strengthen the message to the public that it is important to have that test. And vice versa, a test that is not reimbursed might send a message that it is an unnecessary test. In addition, it is evident that women decide about NIPT in a social context, and may take the perspectives of partners, family members and friends into account, but that does not inevitably amount to societal pressure.

To our knowledge little is known about the influence of public attitudes on women's decision making concerning prenatal screening. In the field of social psychology, research is done on the effects of group pressure on people's opinions. Several experimental studies found that when people face a majority's or an expert's opinion different from their own opinion, they adopt this opinion, even when it includes a wrong judgement $[15,16]$. Translating this to the context of decision making in prenatal screening, pregnant women and couples might (unreflectively) adopt a dominant societal attitude towards NIPT, also when it would not fit their personal attitude towards this test. To assess whether this pressure from societal attitudes might arise it is first important to investigate public moral attitudes towards prenatal screening. This might provide insight into the possible presence of predominant attitudes that might lead to pressure to test or to abort an affected pregnancy. The objective of this study was therefore to examine the attitudes of Dutch citizens towards the decision to decline NIPT and to study the possible impact of funding policies on citizens' attitudes. Furthermore, this study investigated the assumption that women and couples are expected by society to terminate the pregnancy when they learn about the presence of a disorder. It additionally explored respondents' underlying reasons for their attitudes. Second for the assessment of societal pressure and its impact on women's decision making it is also important to assess pregnant women's experiences of pressure. Studying women's experiences falls outside the aim of this study but is already done elsewhere [17, 18].

\section{Method}

In this study, we used the contrastive vignette technique (CVT) in order to prevent soliciting socially desirable responses [19]. With this technique, respondents are presented with one of two contrastive vignettes, while unaware of the contrastive condition and the hypothesis of the study. The vignettes are contrastive in one condition while other variables are kept constant, enabling the identification of factors that affect people's attitudes towards moral issues [19]. The outcome measure of the CVT is the difference in group means between contrastive situations. In this study, the decision to decline a state-funded NIPT was contrasted with the decision to decline a non-reimbursed NIPT and 
termination of an affected pregnancy was contrasted with continuation of an affected pregnancy.

\section{Sample population and survey}

We searched for a sample population representative of the Dutch population. Respondents were recruited via an external Dutch market research agency, Motivaction. Motivaction has an online research panel consisting of 65,000 Dutch members (reference date: April 2018), who participate in (market) research [20]. With filling in online questionnaires on the website www.stempunt.nu panel members earn credits which can be exchanged for gift cards. For this study, Motivaction randomly invited members from their panel until 1096 panel members filled in the questionnaire: for their surveys Motivaction always use groups of $\sim 1000$ participants whereby they strive for a representative sample. The response rate for this survey was $36 \%$. The panel members did not know the topics of the survey beforehand. The study was conducted in September 2017, shortly after the introduction of NIPT as a firsttrimester prenatal screening test in the Netherlands.

\section{Design of the vignettes}

In a multidisciplinary team, we designed two pairs of contrastive vignettes (Appendix A). In the vignettes, we introduced a third person, a fellow citizen in the person of Hanna, who is pregnant for the first time and has to decide whether or not to take part in NIPT, and, when an abnormality is detected, whether to continue or to terminate the pregnancy. We introduced a third person and not for example 'your sister' or 'your friend' in order to prevent the influence of relationships.

The first pair of vignettes involved the decision to decline NIPT including varying funding conditions (i.e., the test is fully reimbursed contrasted with a test offered at a price of $€ 175)$. In the second set of vignettes, the decision to terminate the pregnancy was contrasted with the decision to continue, primarily in case of Down's syndrome and subsequently in case of Edwards' or Patau's syndrome. The vignettes were pilot tested among acquaintances of the researchers and 23 students following a university minor programme in genetics, and were optimised after this pilot.

\section{Procedure}

Respondents first read a short introduction about NIPT and about Down's, Edwards' and Patau's syndrome. Then every respondent received one vignette of the first pair about declining a reimbursed or non-reimbursed NIPT or of the second pair about termination or continuation of pregnancy. Respondents were randomly assigned to the vignettes. They were asked to indicate on a seven-point Likert scale to what extent they agree with Hanna's decision ('completely disagree' $=1$, 'disagree' $=2$, 'disagree a little' $=3$, 'do not disagree/do not agree' $=4$, 'agree a little' $=5$, 'agree' $=6$ and 'completely agree' $=7$ ). Respondents were asked to explain their answers in a follow-up free-response question. Subsequently, we investigated whether people's attitudes changed when confronted with the contrastive condition, as an additional investigation of the effect of varying reimbursement or disorder-severity conditions. In questions $1 \mathrm{c}$ and $2 \mathrm{c}$, respondents were asked what their attitude would be when the situation was the opposite, thus declining a fully reimbursed NIPT instead of co-payment, or vice versa. In questions $3 \mathrm{c}$ and $4 \mathrm{c}$, respondents were asked what their attitude would be when it concerned a pregnancy affected with Edwards' or Patau's syndrome (Appendix A). It should be noted that the answers on these follow-up questions might be influenced by the preceding questions. When respondents answered a question and clicked through, they could not go back to previous questions. The vignettes were part of a survey from Motivaction consisted of 20-23 questions about several other topics including cheese, internet domains and elevators.

\section{Statistical analysis}

Differences in demographic characteristics were tested between groups for each vignette pair: independent sample $t$-tests were used to test mean age differences and the Chisquare statistic was used to test differences with respect to the remaining variables. We tested for each vignette the possible impact of sex, education and income on mean agreement, with a one way ANOVA and correlation between age and agreement. To investigate differences in agreement between groups within each pair of vignettes, independent sample $t$-tests were conducted. Differences in agreement within groups, between questions a and $\mathrm{c}$, were tested with paired sample $t$-tests.

We were specifically interested in 'disagreement' with the choice presented in the vignette because when people disagree with each other, particularly when a majority holds a different attitude, this might affect the individual's attitude, not because of a change in this person's own values but because of the values of others [15]. To compare the group who disagreed with those who did not agree or disagree and those who agreed, in a second step we transformed the seven-point Likert scale into three distinctive subcategories: 'Disagree' [1-3], 'Do not disagree/do not agree' [4], and 'Agree' [5-7], to see how many people agreed, did not disagree/did not agree and disagreed with the decisions.

For comparing the between-sample difference in proportions choosing the 'Disagree' subcategory, we used the 
two-sample $z$-test available in Epitools at http://epitools. ausvet.com.au. Data were analysed with IBM SPSS Statistics 25. The effect size for between and within groups mean differences was expressed as Cohen's $d$ for respectively independent and paired means [21] and interpreted according to Cohen's standard rules of thumb: $0.20=$ 'small', 0.50 'medium', $0.80=$ 'large'. The level of significance was defined as $p<0.05$.

All free-response answers were exported from the data set. AKK and IMB coded the answers independently. Afterwards the codes and discrepancies were discussed until consensus was reach. Then the data set was recoded which result in a list of 14 different explanations of participants concerning their attitudes towards NIPT or termination of pregnancy. The codes and therewith the different explanations were quantified in order to obtain numbers and percentages of how many participants expressed a certain attitude.

\section{Results}

\section{Sample characteristics}

In total, 1096 panel members participated in the study. The mean age of this group was 50.6 years, $49.4 \%$ was man and $50.6 \%$ woman (Table 1). This is representative for the Dutch population.

No significant differences were found in demographic variables between the two groups of each pair of vignettes. Some demographic variables were significantly related to attitudes: in vignettes 1 and 2 significantly more women agreed with the decision to decline NIPT than men. And in the vignettes $1 \mathrm{c}, 2 \mathrm{a}$ and $2 \mathrm{c}$ in the northern and eastern regions of the Netherlands respondents agreed significantly more with the decision to decline NIPT than in the western and southern regions. In vignette $3 \mathrm{c}$, people from the south agreed significantly more with termination for Edwards' or Patau's syndrome than people in the north.

The results provide insight firstly in differences in participants' attitudes towards declining a reimbursed or a nonreimbursed test and towards the decision to continue or terminate a pregnancy of a child with Down's syndrome. They furthermore reveal that respondents frequently mentioned four important explanations for their stated attitudes including freedom of choice, necessity of testing, valuing life, and quality of life.

\section{Attitudes towards declining NIPT and the impact of reimbursement}

Respondents' attitudes in vignettes 1 and 2 revealed that the mean agreement with Hanna's choice to decline NIPT in vignette 1 , in which NIPT was fully reimbursed, was significantly lower than in vignette 2 , where NIPT required an out of pocket co-payment of $€ 175$ ( $p=0.006$, Table 2). In line with this finding, the subgroup percentages showed that significantly more people disagreed with declining a reimbursed NIPT ( $p=0.002$, Table 2). The first of the four most indicated explanations in the total sample for agreeing or being neutral (not agreeing and not disagreeing) was that this decision to decline is someone's personal choice (Appendix B, Table B1): 'It is her decision, I should not have an opinion about that'.

Furthermore, most of the respondents who disagreed with the decision to decline a fully reimbursed as well as a non-reimbursed NIPT did so because they thought that availability of a test offers courses of action, creates a responsibility to test, or costs society too much money (Appendix B, Table B1): 'It is not necessary anymore to bring a handicapped child into the world. Firstly from a moral point of view, secondly because of the costs (healthcare is already unaffordable)'.

The second of four most offered explanations for agreeing or being neutral was a perceived lack of necessity. Some respondents expected a low chance of having a disabled child or a low risk because of the younger age of Hanna-Hanna's age was not mentioned in the vignette, but people thought that she was young, because she was pregnant for the first time. They therefore thought that it was not necessary to test and consequently agreed with declining NIPT.

When both groups of respondents were confronted with the contrastive condition in questions $1 \mathrm{c}$ and $2 \mathrm{c}$ no significant changes occurred within vignette 1 , in which then NIPT cost $€ 175$. But within vignette 2 , in which then the NIPT was fully reimbursed the mean of the Likert-scale answer in $2 \mathrm{c}$ was significantly lower than in $2 \mathrm{a}(t(265)=$ $4.74, p<0.001, d=0.22$ ). As a result, the difference between vignettes 1 and 2 was not significant $(p=0.791$, Table 2). Apparently, when respondents first read about a NIPT costing $€ 175$ and then about a reimbursed NIPT, they tended to agree less with declining a reimbursed test. A $X^{2}$ test showed that there were no significant differences between vignette groups with respect to different income groups $\left(X^{2}[9]=2.98, p=0.965\right)$ Most of those respondents indicated that availability creates a certain responsibility (Appendix B2, Table B1): 'Then [when NIPT is reimbursed] it belongs to standard prenatal screening and there will be good reasons to offer it to every pregnant woman. A waste of opportunity to reject it'. Besides, fewer respondents agreed with declining a reimbursed NIPT than with declining a non-reimbursed NIPT because of a perceived lack of necessity of the test (2c: $12.8 \%$ resp. 2a: 22.7\%, Appendix B, Table B1). This suggests that perception of necessity is influenced by reimbursement policy. 
Table 1 Group characteristics.

\begin{tabular}{|c|c|c|c|c|c|c|c|c|c|c|c|}
\hline & & \multicolumn{10}{|c|}{ Vignet version } \\
\hline & & \multicolumn{2}{|l|}{ Total } & \multicolumn{2}{|l|}{ Vignet 1} & \multicolumn{2}{|l|}{ Vignet 2} & \multicolumn{2}{|l|}{ Vignet 3} & \multicolumn{2}{|l|}{ Vignet 4} \\
\hline & & $\begin{array}{l}\text { Mean } \\
\text { (range) }\end{array}$ & $\%(n)$ & $\begin{array}{l}\text { Mean } \\
\text { (range) }\end{array}$ & $\%(n)$ & $\begin{array}{l}\text { Mean } \\
\text { (range) }\end{array}$ & $\%(n)$ & Mean & $\%(n)$ & Mean & $\%(n)$ \\
\hline Age & & $\begin{array}{l}50.59 \\
(15-70)\end{array}$ & 1096 & $\begin{array}{l}51.04 \\
(15-70)\end{array}$ & 268 & $\begin{array}{l}50.06 \\
(18-70)\end{array}$ & 266 & $\begin{array}{l}50.72 \\
(15-70)\end{array}$ & 306 & $\begin{array}{l}50.51 \\
(17-70)\end{array}$ & 258 \\
\hline \multirow[t]{2}{*}{ Sex } & Man & & 49.4 (541) & & 50.7 (136) & & $46.2(123)$ & & $50.3(153)$ & & 50.0 (129) \\
\hline & Woman & & $50.6(555)$ & & 49.3 (132) & & $53.8(143)$ & & 49.7 (151) & & 50.0 (129) \\
\hline \multirow[t]{6}{*}{ Residence } & 3 biggest cities ${ }^{\mathrm{a}}$ & & 10.9 (119) & & 9.7 (26) & & $11.3(30)$ & & $11.8(36)$ & & $10.5(27)$ \\
\hline & West $^{b}$ & & $29.2(320)$ & & $27.6(74)$ & & $30.8(82)$ & & $28.3(86)$ & & $30.2(78)$ \\
\hline & North $^{c}$ & & $9.1(100)$ & & $7.5(20)$ & & $10.2(27)$ & & $9.2(28)$ & & $9.7(25)$ \\
\hline & East $^{\mathrm{d}}$ & & 19.7 (216) & & $20.9(56)$ & & $19.9(53)$ & & $19.1(58)$ & & $19.0(49)$ \\
\hline & South $^{\mathrm{e}}$ & & $26.5(290)$ & & $29.9(80)$ & & $23.3(62)$ & & $27.0(82)$ & & $25.6(66)$ \\
\hline & Border towns ${ }^{\mathrm{f}}$ & & $4.7(51)$ & & $4.5(12)$ & & $4.5(12)$ & & $4.6(14)$ & & $5.0(13)$ \\
\hline \multirow[t]{3}{*}{ Education $^{\mathrm{g}}$} & High & & 28.8 (316) & & $26.1(70)$ & & $32.0(85)$ & & $28.6(87)$ & & $28.7(74)$ \\
\hline & Middle & & $52.1(571)$ & & $54.5(146)$ & & 47.7 (127) & & $54.3(165)$ & & $51.6(133)$ \\
\hline & Low & & 19.1 (209) & & $19.4(52)$ & & $20.3(54)$ & & $17.1(52)$ & & $19.8(51)$ \\
\hline \multirow[t]{4}{*}{ Income $^{\mathrm{h}}$} & Below median & & $32.9(361)$ & & $31.7(85)$ & & 32.7 (87) & & 31.9 (97) & & $35.7(92)$ \\
\hline & Median & & 12.4 (136) & & $14.6(39)$ & & $11.3(30)$ & & $11.8(36)$ & & $12.0(31)$ \\
\hline & Above median & & 29.7 (326) & & $29.9(80)$ & & $30.5(81)$ & & 30.9 (94) & & $27.5(71)$ \\
\hline & Unknown & & 24.9 (273) & & $23.9(64)$ & & $25.6(68)$ & & $25.3(77)$ & & $24.8(64)$ \\
\hline \multirow{5}{*}{$\begin{array}{l}\text { How many } \\
\text { children do } \\
\text { you have }\end{array}$} & 0 & & 32.7 (358) & & $34.0(91)$ & & $33.8(90)$ & & 30.9 (94) & & $32.2(83)$ \\
\hline & 1 & & 12.4 (136) & & $13.8(37)$ & & $10.2(27)$ & & $12.8(39)$ & & $12.8(33)$ \\
\hline & 2 & & 33.7 (369) & & $28.4(76)$ & & 36.5 (97) & & 34.5 (105) & & $35.3(91)$ \\
\hline & 3 & & 13.3 (146) & & $14.9(40)$ & & $12.4(33)$ & & $14.1(43)$ & & $11.6(30)$ \\
\hline & $\geq 4$ & & & & $9.0(24)$ & & $7.1(19)$ & & $7.6(23)$ & & $8.1(21)$ \\
\hline
\end{tabular}

a bigger cities: Amsterdam, Rotterdam, Den Haag.

${ }^{\mathrm{b}}$ West (Utrecht, Noord-Holland, Zuid-Holland; excl 3 cities and border towns).

${ }^{\mathrm{c}}$ North (Groningen, Friesland, Drenthe).

${ }^{\mathrm{d} E a s t}$ (Overijssel, Gelderland, Flevoland).

${ }^{\text {e}}$ South (Zeeland, Noord-Brabant, Limburg).

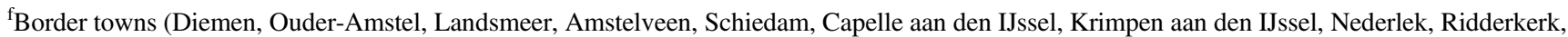
Barendrecht, Albrandswaard, Leidschendam, Voorburg, Rijswijk, Wassenaar, Wateringen).

${ }^{\mathrm{g}}$ High (Master/Bachelor) Middle (High school, (preparatory) secondary vocational education) Low (practice-oriented vocational education primary school, no education).

${ }^{\mathrm{h}}$ Median income is $€ 33,500.00-€ 39,999.00$.

It is noteworthy that fewer respondents disagreed with declining NIPT because 'testing provides courses of action' in 1c compared to 1a (10.4\% resp. 31.3\%, Appendix B, Table B1), which also suggests that reimbursement policy affects respondents' attitudes: 'When it costs money, I understand it better. Maybe Hanna cannot pay $€ 175$. That is a lot of money'. Exploratory additional analysis showed that the difference between 'state-funding vs nonreimbursement' was not significantly associated with income.

In sum, the most important explanation respondents gave for agreeing with or being neutral about declining NIPT is that it is someone's personal decision. Second, the perceived lack of necessity of testing was a frequently indicated reason to agree with declining NIPT. But reimbursement affected respondents' attitudes: when NIPT was fully reimbursed respondents were less likely to agree with declining NIPT.

\section{Attitudes towards termination or continuation of pregnancy and the impact of severity}

Respondents' agreement with the decision to terminate a pregnancy in case of Down's syndrome (vignette 3a) did 
Table 2 Comparison of vignette 1 and vignette 2, reimbursed NIPT vs co-paid NIPT.

\begin{tabular}{|c|c|c|c|c|c|c|c|}
\hline & $\begin{array}{l}\text { Agreement }^{\mathrm{a}} \mathrm{M} \\
\text { (SD), Mdn }\end{array}$ & $\begin{array}{l}\text { Difference M1 vs M2, } \\
t \text { (df) }\end{array}$ & $\begin{array}{l}\text { Difference M1 vs M2 effect } \\
\text { size (d) }\end{array}$ & $\begin{array}{l}\text { Agree \% } \\
(n)\end{array}$ & $\begin{array}{l}\text { Do not disagree/not agree } \\
\%(n)\end{array}$ & $\begin{array}{l}\text { Disagree } \% \\
(n)\end{array}$ & $\begin{array}{l}\text { Disagree } \\
\% 1 \text { vs } 2\end{array}$ \\
\hline $\begin{array}{l}\text { 1a Declining a reimbursed test } \\
n=268\end{array}$ & 4.35 (1.80), 4 & $p=0.006,-2.75(532)$ & 0.240 & $44.8(120)$ & $24.3(65)$ & $31.0(83)$ & $3.1 * *$ \\
\hline $\begin{array}{l}\text { 2a Declining a test which } \\
\text { costs } € 175 \\
n=266\end{array}$ & 4.77 (1.75), 5 & & & $53.0(141)$ & $27.4(73)$ & $19.5(52)$ & \\
\hline $\begin{array}{l}\text { 1c Declining a test which } \\
\text { costs } € 175 \\
n=268\end{array}$ & 4.41 (1.73), 4 & $\begin{array}{l}p=0.791,0.27 \\
(525.67)\end{array}$ & 0.022 & 46.3 (124) & $28.7(77)$ & $25.0(67)$ & $0.8^{*}$ \\
\hline $\begin{array}{l}\text { 2c Declining a reimbursed test } \\
n=266\end{array}$ & 4.37 (1.92), 4 & & & $47.0(125)$ & $24.8(66)$ & $28.2(75)$ & \\
\hline
\end{tabular}

Cohen's [21]: $d=0.20$ small; $0.50=$ medium; $0.80=$ large.

$* p<0.05 ; * * p<0.01$.

${ }^{\mathrm{a}}$ Measured on a seven-point Likert scale.

Table 3 Comparison of vignette 3 and vignette 4, termination vs continuation of pregnancy.

\begin{tabular}{|c|c|c|c|c|c|c|c|}
\hline & $\begin{array}{l}\text { Agreement }{ }^{\mathrm{a}} \mathrm{M} \\
\text { (SD), Mdn }\end{array}$ & $\begin{array}{l}\text { Difference M1 vs } \\
\text { M2, } t \text { (df) }\end{array}$ & $\begin{array}{l}\text { Difference M1 vs M2 } \\
\text { effect size }(d)\end{array}$ & $\begin{array}{l}\text { Agree \% } \\
(n)\end{array}$ & $\begin{array}{l}\text { Do not disagree/not } \\
\text { agree } \%(n)\end{array}$ & $\begin{array}{l}\text { Disagree } \\
\%(n)\end{array}$ & $\begin{array}{l}\text { Disagree } \% 3 \\
\text { vs } 4 z\end{array}$ \\
\hline $\begin{array}{l}\text { 3a Deciding to terminate the pregnancy of a child with } \\
\text { Down's syndrome } \\
n=304\end{array}$ & 4.64 (1.817), 5 & $\begin{array}{l}p=0.080 \\
-1.75(560)\end{array}$ & 0.146 & $53.3(163)$ & $25.0(76)$ & $21.7(66)$ & $1.5^{*}$ \\
\hline $\begin{array}{l}\text { 4a Deciding to continue the pregnancy of a child with } \\
\text { Down's syndrome } \\
n=258\end{array}$ & 4.90 (1.752), 5 & & & 57.4 (149) & $26.0(67)$ & $16.7(43)$ & \\
\hline $\begin{array}{l}\text { 3c Deciding to terminate the pregnancy of child with } \\
\text { Edwards' or Patau's syndrome } \\
n=304\end{array}$ & 4.90 (1.729), 6 & $\begin{array}{l}p<0.001,5.58 \\
(547.76)\end{array}$ & 0.472 & 54.9 (168) & $29.9(91)$ & $15.1(46)$ & $3.7 * * *$ \\
\hline $\begin{array}{l}\text { 4c Deciding to continue the pregnancy of a child with } \\
\text { Edwards' or Patau's syndrome } \\
n=258\end{array}$ & 4.09 (1.703), 4 & & & $34.1(89)$ & $38.0(98)$ & $27.9(72)$ & \\
\hline
\end{tabular}

Cohen's [21]: $d=0.20$ small; $0.50=$ medium; $0.80=$ large.

$* p<0.05, * * * p<0.01$

${ }^{\mathrm{a}}$ Measured on a seven-point Likert scale.

not differ significantly from agreement with the decision to continue a pregnancy in case of Down's syndrome (vignette $4 a$ ), $p=0.080$ (Table 3). Neither did the subgroup percentages show any difference in agreement. This suggests that the public does not prefer one course of action above the other: the decision to terminate or continue a pregnancy after a prenatal diagnosis of Down's syndrome would meet the same public attitude. As with the previous pair of vignettes, respondents indicated that the decision to terminate or continue an affected pregnancy is someone's own choice to make. The most frequently indicated reason to disagree with termination was that someone has to accept life as it comes and should accept every child (Appendix B, Table B2). This was also the third of the top four explanations in general. Within this group most respondents thought that every child should be accepted because they were against abortion.

In the group that agreed with termination of the pregnancy or disagreed with continuation the most frequently indicated reason was that it is in the child's or parents' best interest to end the pregnancy, respectively $33.3 \%$ and $37.2 \%$, which is the fourth most frequently indicated explanation in the total sample. Respondents thought that it takes too much from parents to raise a disabled child or that the child is awaiting a low quality of life, being always dependent on the parents and the community.

We further wanted to know in questions $3 \mathrm{c}$ and $4 \mathrm{c}$ whether respondents' attitudes would change when the decision to terminate or continue concerns more severe disorders, i.e. Edwards' or Patau's syndrome. Most children with these aneuploidies are not viable. The severity of a disorder affected respondents' attitude: respondents were more likely to disagree with continuation of a pregnancy in case of trisomy 13 or 18 , or agree more with termination of a pregnancy in case of such severe chromosomal aberrations $(p<0.001$, Table 3$)$.

The mean attitudes towards the decision to terminate or continue the pregnancy also changed significantly within both groups: respondents changed their mind in case of more severe disorders. Respondents in vignette 3 agreed more with termination of pregnancy in case of trisomy 13 or 18 compared to trisomy $21(t(303)=-5.04, p<0.001, d=$ $0.15)$. Likewise, in vignette 4 , more people disagreed with continuation of pregnancy in case of trisomy 13 or 18 
compared to trisomy $21(t(257)=9.45, p<0.001, d=$ 0.47). Most respondents stated that a reason for them to agree with termination or disagree with continuation of pregnancy in case of trisomy 13 or 18 was that termination is in the best interest of the child, sometimes indicating that Edwards' or Patau's syndrome is more severe: 'A child with Down's syndrome can still be happy but with this handicap you cannot. There is no life expectancy [for children with Edwards' or Patau's syndrome]'.

In sum, the detected attitudes towards the decision to decline NIPT and the decision to terminate or continue an affected pregnancy revealed not one but at least four major societal attitudes towards NIPT: 'It is someone's own choice', 'It is not necessary to test', 'One must accept every child' and 'Testing is in the best interest of parents and child'. Besides, $13.1 \%$ gave no explanation and $13.8 \%$ gave somewhat generic or just personal explanations, like 'I would make the same decision', 'I would never have a handicapped child', and 'I do not have enough information about Hanna's personal situation', which were classified as 'other'.

\section{Discussion}

This contrastive vignettes study provided valuable insights into public attitudes in the Netherlands towards the decision of a pregnant fellow citizen to decline NIPT and towards termination or continuation of pregnancy. Also, it sheds light on the impact of reimbursement policies and of the severity of disorders included in NIPT on these attitudes. The most remarkable finding was that a majority of the respondents either agreed with or did not have an outspoken opinion about the decision of a pregnant woman to decline either a fully state-funded NIPT or a NIPT requiring a copayment of $€ 175$ because these decisions are considered to be personal in nature. This suggests that Dutch citizens acknowledge the importance of free choice, and that society leaves room for personal decision making concerning prenatal screening, which is a prerequisite for autonomous reproductive choices. The results of this study may help to rebut the ethical concern that NIPT leads women to be pressured into accepting the prenatal screening offer. Furthermore many respondents did not have a dominant preference for either termination or continuation of pregnancy in case of a diagnosis of Down's syndrome-which also supports this. Moreover, respondents' explanations revealed some degree of diversity in public attitudes towards NIPT and termination of pregnancy. The existence of a range of public attitudes-we have identified four major attitudes and many (minor) others - regarding NIPT theoretically provides pregnant women and couples with room to conceive personal attitudes.
This study also showed that funding policies affect public attitudes towards NIPT. Respondents agreed less with declining a fully funded NIPT and agreed more with declining a NIPT for which a co-payment was required. This suggests that state funding of NIPT might influence public attitudes towards declining prenatal screening. Offering a fully reimbursed test seemed to provoke amongst a small group the idea that NIPT becomes an offer one cannot refuse, suggesting a legitimising effect for accepting prenatal testing. This finding might fuel the fear which was previously indicated in the literature by pregnant women and parents of children with Down's syndrome namely for self-evident acceptance of NIPT among pregnant women, and societal moral judgements on those who decline screening $[5,6,10]$. But whether pregnant women will be influenced by a funding policy and the possible related public attitudes should be asked to women themselves. In one interview study women suggested that state-funding might carry the message that prenatal screening is standard practice but this is still hypothetical, further study of women's personal decision making is necessary [18]. On the other hand, requiring a co-payment might contribute to the misunderstanding that reimbursed tests are important and non-reimbursed tests are unnecessary or not applicable to certain (younger) women. Further research should address the influence of funding policies on public attitudes and societal pressure to test.

Attitudes towards termination or continuation of a pregnancy in case of Down's syndrome or Edwards' or Patau's syndrome seemed to be shaped in first instance by attitudes towards abortion. Second, they were shaped by how respondents perceived living with these syndromes. This study's findings about the impact of the severity of the disorder and its expected burden for children and their parents are relevant in light of recent discussions on the technical possibilities for expanding the scope of NIPT, allowing for the assessment of many more genetic disorders. Societal support for inclusion of more disorders in a prenatal screening programme will vary with the severity of the disorders. This might be relevant when thinking about the possible expansion of the scope of prenatal screening.

Furthermore, the current study showed that a small subgroup within the Dutch population has a negative attitude towards declining NIPT or giving birth to a disabled child, pointing at parental responsibility or social costs. The finding that this is a small group might fend off existing fears of future societal pressure as expressed by pregnant women, professionals and parents of children with trisomy 21,13 or $18[5,10,22,23]$. Nevertheless, since these attitudes exist, during counselling, professionals could investigate whether women experience pressure from societal attitudes and pay extra attention to women's free and personal decision making. The current study does not 
provide insight in the extent to which women recognise or feel influenced by these kinds of expressed attitudes. Whether these experiences are present amongst women should be asked to women themselves as already done in previous studies. In these studies, women reported that they felt free to decide about prenatal screening independently $[8,17,24]$. But the question is whether women will always be aware of societal pressure if it exists. Therefore, the interaction between women's and public attitudes merits further scrutiny to understand the effects of societal pressure and ways to counter it.

The strengths of this study are the large representative sample population, the heterogeneity within groups and comparability between groups. However, demographic information on respondents' views on life or religious convictions was not asked. Religious convictions are known to influence attitudes towards prenatal screening and termination of pregnancy [25]. This might explain that in the current study, respondents from the eastern region agreed significantly more with the decision to decline NIPT, as the population in the eastern region of the Netherlands is more conservatively religious than in the western region. Previous research found a low uptake of the first-trimester combined test in this region [25]. Furthermore, we found that termination and continuation met the same public attitudes, but the distribution of those who agreed with termination actually differed between the vignettes: in vignette 3 more people were pro termination and in vignette 4 more people were pro continuation. In vignette $4 \mathrm{a}$, we used the phrase 'continuing the pregnancy and keeping the baby'. Possibly the word 'baby' made the vignette feel more personal to respondents and elicited moral intuitions about the life of the future child. For the formulation of the vignettes, we had to deal with on the one hand the comparability of the vignettes and on the other hand natural language. Although 'continuation' and 'termination' are more neutral opposite terms, the phrase 'to continue the pregnancy' is not often used in Dutch natural language to describe a decision to 'keep the baby'. This dilemma shows that terminology in vignettes may be value laden and steering. It is outside the scope of this paper, but it would be interesting to study if and how framing and terminology used by counsellors influence pregnant women's decision making.

To conclude, this study showed that within a representative sample of Dutch citizens, personal choice is broadly acknowledged. Also, Dutch society appears to allow for a wide range of attitudes regarding NIPT, which could help to nuance the concern that in the Netherlands, one moral attitude may become predominant and lead to societal pressure to take part in screening and to terminate pregnancies affected by chromosomal abnormalities. However, opinions are partly influenced by the funding policy and by the severity of the disorder. Thus, continued focus on personal decision making in pretest counselling and responsible screening-policy decisions will be required to serve reproductive autonomy. Also, further research in this area should help to maintain freedom of choice with regard to prenatal screening,

Funding This study is a result of a research project 'Towards an ethically robust scope of NIPT' which was funded by ZonMw, dossier number 70-73000-98-116.

\section{Compliance with ethical standards}

Conflict of interest The authors declare that they have no conflict of interest.

Publisher's note Springer Nature remains neutral with regard to jurisdictional claims in published maps and institutional affiliations.

\section{References}

1. Faden RR, Beauchamp TL. A history and theory of informed consent. Oxford: Oxford University Press; 1986.

2. Dondorp W, De Wert G, Bombard Y, Bianchi DW, Bergmann C, Borry $\mathrm{P}$, et al. Non-invasive prenatal testing for aneuploidy and beyond: challenges of responsible innovation in prenatal screening. Eur J Hum Genet. 2015;23:1438-50.

3. Oepkes D, Page-Christiaens GC, Bax CJ, Bekker MN, Bilardo $\mathrm{CM}$, Boon EMJ, et al. Trial by dutch laboratories for evaluation of non-invasive prenatal testing. Part i-clinical impact. Prenat Diagn. 2016;36:1083-90.

4. Kater-Kuipers A, de Beaufort ID, Galjaard RH, Bunnik EM. Ethics of routine: a critical analysis of the concept of 'routinisation' in prenatal screening. J Med Ethics. 2018;44:626-31.

5. Lewis C, Silcock C, Chitty LS. Non-invasive prenatal testing for down's syndrome: Pregnant women's views and likely uptake. Public Health Genom. 2013;16:223-32.

6. van Schendel RV, Kleinveld JH, Dondorp WJ, Pajkrt E, Timmermans DRM, Holtkamp KCA, et al. Attitudes of pregnant women and male partners towards non-invasive prenatal testing and widening the scope of prenatal screening. Eur J Hum Genet. 2014;22:1345-50.

7. Deans Z, Hill M, Chitty LS, Lewis C. Non-invasive prenatal testing for single gene disorders: Exploring the ethics. Eur J Hum Genet. 2013;21:713-8.

8. Aune I, Möller A. 'I want a choice, but i don't want to decide'-a qualitative study of pregnant women's experiences regarding early ultrasound risk assessment for chromosomal anomalies. Midwifery. 2012;28:14-23.

9. Wilkinson S. Prenatal screening, reproductive choice, and public health. Bioethics. 2015;29:26-35.

10. van Schendel RV, Kater-Kuipers A, van Vliet-Lachotzki EH, Dondorp WJ, Cornel MC, Henneman L. What do parents of children with down syndrome think about non-invasive prenatal testing (nipt)? J Genet Couns. 2017;26:522-31.

11. R. Lindeman TD, B. Slager. Zwartboek downsyndroom. Alle mensen zijn ongelijk en gelijkwaardig; 2016. https://downpride. com/blackbook-down/.

12. Kellogg G, Slattery L, Hudgins L, Ormond K. Attitudes of mothers of children with down syndrome towards noninvasive prenatal testing. J Genet Couns. 2014;23:805-13. 
13. How B, Smidt A, Wilson NJ, Barton R, Valentin C. 'We would have missed out so much had we terminated': What fathers of a child with down syndrome think about current non-invasive prenatal testing for down syndrome. J Intellect Disabil. 2019;23:290-309.

14. Johnston J, Farrell RM, Parens E. Supporting women's autonomy in prenatal testing. N Engl J Med. 2017;377:505-7.

15. Asch SE. Opinions and social pressure. Sci Am. 1955;193:31-5.

16. Moussaïd M, Kämmer JE, Analytis PP, Neth H. Social influence and the collective dynamics of opinion formation. PLOS ONE. 2013;8:e78433.

17. Jaques AM, Bell RJ, Watson L, Halliday JL. People who influence women's decisions and preferred sources of information about prenatal testing for birth defects. Aust N Z J Obstet Gynaecol. 2004;44:233-8.

18. Bakkeren IM, Kater-Kuipers A, Bunnik EM, Go AT, Tibben A, de Beaufort ID, et al. Implementing non-invasive prenatal testing (NIPT) in the netherlands: An interview study exploring opinions about and experiences with societal pressure, reimbursement, and an expanding scope. J Genet Couns. 2019; 29:112-21.
19. Burstin K, Doughtie EB, Raphaeli A. Contrastive vignette technique: an indirect methodology designed to address reactive social attitude measurement. J Appl Soc Psychol. 1980;10:147-65.

20. Motivaction International. Motivaction research and strategy; 2018 https://www.motivaction.nl/en/.

21. Cohen J. A power primer. Psychol Bull. 1992;112:155.

22. Guon J, Wilfond BS, Farlow B, Brazg T, Janvier A. Our children are not a diagnosis: The experience of parents who continue their pregnancy after a prenatal diagnosis of trisomy 13 or 18 . Am J Med Genet Part A. 2014;164:308-18.

23. Birko S, Ravitsky V, Dupras C, Le Clerc-Blain J, Lemoine M-E, Affdal AO, et al. The value of non-invasive prenatal testing: preferences of canadian pregnant women, their partners, and health professionals regarding nipt use and access. BMC Pregnancy Childbirth. 2019;19:22.

24. García E, Timmermans DRM, Van Leeuwen E. Rethinking autonomy in the context of prenatal screening decision-making. Prenat Diagn. 2008;28:115-20.

25. Crombag N, Schielen PCJI, Hukkelhoven CW, Iedema R, Bensing JM, Visser GH, et al. Determinants of first trimester combined test participation within the central region of the netherlands. Prenat Diagn. 2015;35:486-92. 